\title{
Diagnosis and Management of Alcohol Use Disorder in Patients with Liver Disease: Lights and Shadows
}

\author{
Giovanni Addolorato $^{1,2}$ - Gabriele A. Vassallo ${ }^{1,3}$ - Antonio Mirijello ${ }^{1,4}$ • Antonio Gasbarrini ${ }^{2,5}$
}

Published online: 11 November 2019

(C) The American Society for Experimental NeuroTherapeutics, Inc. 2019

\begin{abstract}
Alcohol use disorder is the most common cause of advanced liver disease in the Western world. Diagnosis of alcohol use disorder can be difficult because patients with liver disease tend to deny alcohol intake for the fear of being excluded from treatment and because available biomarkers of alcohol intake have poor specificity in these patients. Alcohol abstinence is the cornerstone of the therapy in these patients. However, pharmacological treatments for alcohol use disorders have not been formally tested in patients with advanced liver disease, except for baclofen. Psychosocial intervention became crucial in these patients considering the limited pharmacological choice. However, psychosocial approach and an appropriate team to manage these patients are not still well defined. In this review, we critically discuss the diagnosis and the management of alcohol use disorder in patients with liver disease.
\end{abstract}

Key Words Alcohol use disorder $\cdot$ alcoholic liver disease $\cdot$ alcoholic cirrhosis $\cdot$ anti-craving drugs $\cdot$ psychosocial approach $\cdot$ liver transplantation

\begin{abstract}
Abbreviations
AUD Alcohol use disorder

ALD Alcohol-related liver disease

AWS Alcohol withdrawal syndrome
\end{abstract}

\section{Key Points}

- Alcohol use disorder is the most common cause of liver disease in the Western world.

- AUDIT and CAGE are useful tools to screen alcohol use disorder, although diagnosis is made when DSM-V criteria are fulfilled.

- Biological markers can help physicians to detect and monitor alcohol intake. Among them, direct biomarkers are better to detect alcohol intake in patients with liver disease; indirect biological markers have a low specificity in this population of patients.

- Among pharmacological treatment for alcohol use disorder approved by National Medical Agency, only baclofen has been tested in randomized clinical trials in patients with liver disease, showing efficacy and safety in this population.

- Psychosocial-integrated approach is useful for this population of patients, although questions about the type of psychosocial support and appropriate team to manage it are still opened.

Invited review for Special Issue on "Neurobiological Targets in Translational Addiction Research"

Giovanni Addolorato

giovanni.addolorato@unicatt.it

Extended author information available on the last page of the article
LD Liver disease

RCTs Randomized controlled trials

\section{Introduction}

Alcohol use disorder (AUD) is a chronic and relapsing condition characterized by harmful alcohol intake leading to multiorgan damage, injuries [1] and behavioral-cognitive alterations. Effects of alcohol consumption are estimated to be accountable to $3.8 \%$ of all global deaths and $4.6 \%$ of global disability-adjusted life-years attributable to alcohol [1]. The costs associated with alcohol amount to more than $1 \%$ of the gross national product in high-income and middle-income countries.

AUD is also associated with impaired productivity and interpersonal functioning, financial burdens [1], motor vehicle crashes, violence and property crime [2].

The worldwide prevalence of AUD is $4.1 \%$ to $5.1 \%$, which seems to be higher in industrialized or developed countries [3]. AUD is responsible for over 3 million deaths every year in the world [3]. AUD is the third leading risk factor for morbidity and mortality after tobacco and hypertension in Europe [4]. 
AUD is the most common cause of advanced liver disease (LD) in the Western world [5] which accounts for a large portion of alcohol-related morbidity and mortality. The alcohol-attributable fraction of liver cirrhosis is up to $60 \%$ in both Europe and North America [6]. In 2010, alcohol-related liver disease (ALD) caused half a million deaths worldwide, accounting for $50 \%$ of global liver disease-related mortality. An additional 80,000 deaths resulted from alcohol-related hepatocellular carcinoma [1, 7]. At present, ALD is the most common indication for liver transplantation (LT) in Europe and North America [8].

Despite this alarming frequency, only few patients receive proper treatment for AUD [9]. Moreover, the management of AUD in patients with LD is poorly investigated and emerging data indicate that this population requires a different approach with respect to AUD patients without LD [10].

In this review, the specific tools for diagnosis, biological markers to monitor alcohol consumption, safe and effective alcohol abstinence-oriented treatments for AUD patients with LD were critically discussed.

\section{Diagnosis of Alcohol Use Disorders in Patients with Liver Disease}

Clinical interview, past medical history and information regarding alcohol consumption, including amount and drinking patterns (i.e., binge drinking or heavy drinking), are mandatory in the AUD diagnostic framework. The amount of alcohol intake could be registered by using standard drink units that range from 8-10 g of alcohol in European countries to 13$14 \mathrm{~g}$ in North America [11]. However, even if information on drinking patterns is adequately collected (i.e., in an empathic and nonjudgmental manner), the clinical interview could not be reliable, because many AUD patients deny or underreport their alcohol intake. Validated tools should be used to support the clinical interview. The most common screening tests used to assess alcohol abuse and dependence are the Alcohol Use Disorders Inventory Test (AUDIT) [12] and Cut downAnnoyed-Guilty-Eye opener (CAGE) [13]. The AUDIT is a 10-question test developed by the World Health Organization in 1982 to screen risky drinking. This test has a good sensitivity $(95 \%)$ and specificity ( $85 \%)$; it has also been validated across genders and in a wide range of racial/ethnic groups [12]. A total score above 8 indicates a diagnosis of AUD, scores between 8 and 15 indicate harmful drinking behavior, while scores above 15 indicate the presence of alcohol dependence [14]. AUDIT-c, a shorter form of AUDIT, is available. It is based on the first 3 items of alcohol consumption of AUDIT; a score of 6 or more for men and 4 or more for women is considered positive [15].

CAGE remains one of the most widely used screening tools for detecting alcohol abuse in clinical practice (i.e., by general physician). CAGE questionnaire is based on 4 yes/no questions; the positive answer to 2 of them indicates the possible presence of AUD [13]. However, CAGE seems to be less sensitive (ranging from 79 to $97 \%$ ) and specific (ranging from 77 to $94 \%$ ) than AUDIT [16].

If the CAGE or AUDIT indicates the presence of AUD, other details about history of alcohol consumption should be obtained from the patient and its family members or caregiver. This information includes both past alcohol consequences (legal, social, occupational) and medical complications (alcoholrelated disease and withdrawal symptoms when patients have promptly reduced or stopped alcohol intake).

AUDIT and CAGE are screening tests, while the gold standard for the diagnosis of AUD is represented by the Diagnostic and Statistical Manual of Mental Disorders 5th edition criteria [17]. The latter is based on the occurrence of at least 2 of 11 criteria, and the severity of disease is directly proportional to the number of positive criteria. According to these criteria, the distinction between alcohol abuse and alcohol dependence present in the previous version has been removed, being now considered as 2 different stages of the same disease [17].

\section{The Biological Markers to Detect Alcohol Use Disorder and Monitor Alcohol Consumption in Patients with Liver Disease}

Due to fear to be excluded from treatment (i.e., hepatitis $\mathrm{C}$ drugs, liver transplantation) and to be stigmatized by the physician, some patients could deny their alcohol abuse or drinking habits [9]. In this case, biomarkers can help clinician to detect alcohol consumption. These include ethanol and several indirect and direct biomarkers of alcohol abuse (Table 1).

Ethanol can be routinely detected in blood, exhaled breath and urine. The detection of ethanol concentration, due to its short half-life, is useful only to detect acute alcohol intoxication, but it shows limited utility to evaluate alcohol abstinence, given the relatively short detection window (blood ethanol concentration decreases at a rate of $0.15 \mathrm{~g} / \mathrm{L} / \mathrm{h}$ ) [18].

The indirect biological markers for alcohol abuse are the result of the interference of ethanol with biochemical processes and the result of ALD which shows different sensitivity and specificity levels to detect harmful drinking [18]. The consumption between 80 and $200 \mathrm{~g}$ of ethanol per day for several weeks can increase the serum $\gamma$-glutamyltransferase level. However, several pathological processes can also increase $\gamma$ glutamyltransferase levels such as cholestasis, biliary disease, heart failure, pancreas or kidney damage, obesity and type 2 diabetes [18].

The mean corpuscular volume (MCV) is the average volume of the erythrocytes. Chronic alcohol abuse usually increases the size of red blood cells (macrocytosis). As the life span of red blood cells is 120 days, MCV levels normalize 
Table 1 Details about biological markers for alcohol consumption

\begin{tabular}{|c|c|c|c|}
\hline Biomarkers & Pro & Contraindication & Indication \\
\hline Blood alcohol concentration & Widely available and high specificity & Short window detection & Acute alcohol intoxication \\
\hline$\gamma$-Glutamyltransferase & Widely available and cheap & $\begin{array}{l}\text { Low specificity in patients } \\
\text { with liver disease }\end{array}$ & Screening of alcohol use disorder \\
\hline Mean corpuscular volume & Widely available and cheap & Low specificity & Screening of alcohol use disorder \\
\hline AST/ALT ratio $>2$ & Widely available and cheap & $\begin{array}{l}\text { Low specificity in patients } \\
\text { with liver disease }\end{array}$ & $\begin{array}{l}\text { Screening of alcohol-related liver } \\
\text { disease }\end{array}$ \\
\hline Carbohydrate-deficient transferrin & $\begin{array}{l}\text { Detection of heavy drinking } \\
\text { in the last } 2-4 \text { weeks }\end{array}$ & $\begin{array}{l}\text { Short periods of alcohol intake } \\
\text { may remain undetected } \\
\text { Low specificity in patients } \\
\text { with liver disease }\end{array}$ & $\begin{array}{l}\text { During follow-up for detection of } \\
\text { relapse and current heavy drinking } \\
\text { in patients without liver disease }\end{array}$ \\
\hline $\begin{array}{l}\text { Ethyl glucuronide } \\
\text { Ethyl sulfate }\end{array}$ & $\begin{array}{l}\text { If ethyl glucuronide is measured } \\
\text { on the hair, it is a biomarker } \\
\text { for long-term alcohol intake } \\
\text { detection }\end{array}$ & $\begin{array}{l}\text { Short window detection if they } \\
\text { are measured on the urine } \\
\text { sample }\end{array}$ & $\begin{array}{l}\text { During follow-up for detection of } \\
\text { relapse also in patients with liver } \\
\text { disease }\end{array}$ \\
\hline Phosphatidylethanol & $\begin{array}{l}\text { Indicates heavy drinking over a } \\
\text { 3-week period }\end{array}$ & $\begin{array}{l}\text { Not widely available (restricted } \\
\text { to specialized laboratories) }\end{array}$ & $\begin{array}{l}\text { During follow-up for detection of relapse } \\
\text { also in patients with liver disease }\end{array}$ \\
\hline Fatty acid ethyl esters & $\begin{array}{l}\text { If it is measured on the hair, } \\
\text { it is a biomarker for long-term } \\
\text { alcohol intake detection }\end{array}$ & $\begin{array}{l}\text { Not widely available (restricted } \\
\text { to specialized laboratories) } \\
\text { Short window detection if they } \\
\text { are measured on the blood } \\
\text { sample }\end{array}$ & During follow-up for detection of relapse \\
\hline
\end{tabular}

after 3 months to 4 months after alcohol abstinence. However, MCV level is also influenced by several confounding factors, including vitamin $\mathrm{B}_{12}$ or folic acid deficiency, hematological diseases and bone marrow disorders [18].

Aspartate aminotransferase (AST) and alanine aminotransferase (ALT) are less specific as compared to $\gamma$ glutamyltransferase. AST and ALT can be elevated in terms of AST:ALT ratio; in particular, a ratio 2:1 or greater is suggestive of ALD [18].

Carbohydrate-deficient transferrin (CDT) represents the percentage of transferrin isoforms with reduced sialic acid which is produced as a result of alcohol abuse. A consumption of $50 \mathrm{~g}$ to $80 \mathrm{~g}$ of ethanol per day for 1 week to 2 weeks can raise CDT level. As a consequence, short periods of high alcohol consumption (i.e., binge drinking) may remain undetected. The half-life of CDT is about 2 weeks. Among the indirect markers, CDT\% is considered the most reliable marker to detect chronic and excessive alcohol consumption by addiction specialist. However, some conditions (i.e., severe liver disease) can lead to false positive results [19].

Although the combined use of these markers gives a better sensitivity to identify past alcohol consumption, all these biomarkers are also influenced by liver inflammation, biliary tract disease, steatosis and liver cirrhosis; they show diagnostic weakness, giving false-positive results in patients with LD [20]. Thus, they are less useful in patients affected by advanced LD.

Direct biomarkers of ethanol use constitute a set of minor ethanol metabolites, produced by biochemical reactions in which ethanol is coupled to an endogenous molecule.

Ethyl glucuronide and ethyl sulfate are ethanol metabolites, their presence can therefore be correlated to the amount of alcohol used. They can be detected in urine for 4 days to 5 days after regular consumption [20]. While ethyl glucuronide and ethyl sulfate can be quantified in blood and urine, ethyl glucuronide can also be quantified in hair [21]. In a small prospective study, urinary ethyl glucuronide showed to be the strongest one to monitor alcohol consumption [22].

Phosphatidylethanol is a group of aberrant phospholipids formed in the cell membrane by phospholipase D in the presence of ethanol. They can be detected in blood, in case of chronic alcohol abuse they are detectable up to 28 days after sobriety. In comparison to indirect ethanol biomarkers, phosphatidylethanol is demonstrated to have high specificity and sensitivity in the detection of latent ethanol use [23]. Two recent studies reported high specificity and sensitivity of phosphatidylethanol in the detection of alcohol consumption in patients with advanced LD $[23,24]$. 
Fatty acid ethyl esters are a group of more than 20 substances formed by enzymatic esterification of ethanol and free fatty acids. During the first $18 \mathrm{~h}$ after alcohol consumption, 95\% of them detected in serum are eliminated; therefore, dosing them in the hair could be a better option to enhance detection window [18].

In summary, at present, biomarkers able to give certainty about total alcohol abstinence in AUD patients with advanced liver disease are not available. Future investigations on this area are warranted [25].

\section{Management of Alcohol Use Disorder in Patients with Liver Disease}

\section{General Measures}

ALD includes a spectrum of alcohol-induced liver pathology, ranging from steatosis, steatohepatitis, fibrosis, to cirrhosis and hepatocellular carcinoma [26]. The natural history of ALD varies significantly among different individuals and their characteristic pattern of drinking behavior, in which $80 \%$ to $90 \%$ of heavy drinkers will develop steatosis, from them 10-35\% will develop alcoholic hepatitis and only $10 \%$ will progress to cirrhosis [27]. Other than alcohol's direct toxicity, patterns of alcohol consumption, duration and amount of alcohol intake, hepatitis virus infection and interaction with host factors (i.e., gut microbiota, gender, genetic, nutritional factors and comorbidities) are additional factors influencing the development and the progression of ALD [27, 28]. Among them, overweight is the most important risk factor increasing the risk to develop cirrhosis in AUD patients [29]. The coexistence of chronic hepatitis B or C infection also leads to more frequent and faster development of advanced LD.

The goals of treating ALD include minimizing the severity of the clinical and biochemical manifestations, preventing its progression to severe form and its related complications (i.e., esophageal varices bleeding, ascites, hepatocellular carcinoma (HCC)) (Fig. 1). In the early phase of ALD, alcohol discontinuation produces an improvement of liver histology [7, 28]. When inflammatory activity is detectable (i.e., mild elevation of transaminase levels), the use of nonspecific antioxidants (i.e., vitamin $\mathrm{E}$ and other natural antioxidants) could be useful to reduce alcohol-induced oxidative stress, although definite results are lacking [30]. Metadoxine, a drug able to enhance alcohol metabolism by increasing acetaldehyde dehydrogenase activity [31], showed efficacy in reducing laboratory signs of liver necrosis and cholestasis when compared to vitamins or placebo [32].

Chronic alcohol consumption leads to pathological changes in gut microbiota composition that is characterized by small intestine bacterial overgrowth with a relative increase in Proteobacteria [33] and a decrease of Bacteroidetes, a beneficial phylum for gut function [34]. These alterations result in intestinal mucosal inflammation and excessive gut permeability with a consequent increase of bacterial translocation from intestinal lumen to portal blood, producing endotoxin-mediated oxidative stress and liver damage [35]. Different approaches of gut microbiota modulation (i.e., administration of antibiotics, probiotics, prebiotics, and symbiotics) have been tested in patients with ALD. They showed how this modulation could be a strategy to reduce alcohol-induced liver injury and to prevent disease progression, although further prospective studies with a larger sample are useful [34].

Acute alcoholic hepatitis $(\mathrm{AH})$ requires a specific evaluation: its severity and treatment options should be based on Maddrey's discriminant function (DF) and Glasgow Alcoholic Hepatitis score (GAHS). The first represents a score based on prothrombin time and total bilirubin, proposed by Maddrey and colleagues [36] in 1978, showing a good sensitivity and reliability in predicting 28-day prognosis. The second score was validated by Forrest and colleagues [37] in 2005. It considers factors influencing mortality in $\mathrm{AH}$ (age, white blood cell count, blood urea, prothrombin time ratio, and bilirubin) and shows a better specificity than Maddrey's discriminant function in predicting survival at 28 days and 84 days.

Total alcohol abstinence and supportive treatment are usually sufficient for clinical recovery in mild AH. On the contrary, severe $\mathrm{AH}$, characterized by a Maddrey discriminant function $>32$ or a Glasgow Alcoholic Hepatitis score $>9$, requires corticosteroid treatment [38]. Even if previous clinical trials encourage its use for treatment of severe AH [38], a recent randomized placebo-controlled multicenter study from the UK (STOPAH (Steroids or pentoxifylline for alcoholic hepatitis) study) showed only a trend for mortality benefit at 28 days with steroid treatment [39]. However, it should be underlined that in this study, more than $60 \%$ of patients were not abstinent at 1 year of follow-up, suggesting that the high rates of alcohol relapse contributed to the mortality rate and, consequently, to the negative results of the trial. Moreover, a meta-analysis of randomized studies, including STOPAH study, confirmed that corticosteroids were effective in reducing short-term mortality [40]. The addition of $N$ acetylcysteine to corticosteroid therapy appears to improve the prognosis of these patients, reducing the rate of infectious complications and hepatorenal syndrome [41]. The existing evidence does not support the use of pentoxifylline in patients with severe AH [39, 42].

Given the high rate of malnutrition and its related mortality in patients affected with ALD, nutritional support is a crucial component [43]. Adequate protein 


\section{Targets for the treatment of patients with Alcohol Use Disorder and Liver Disease}

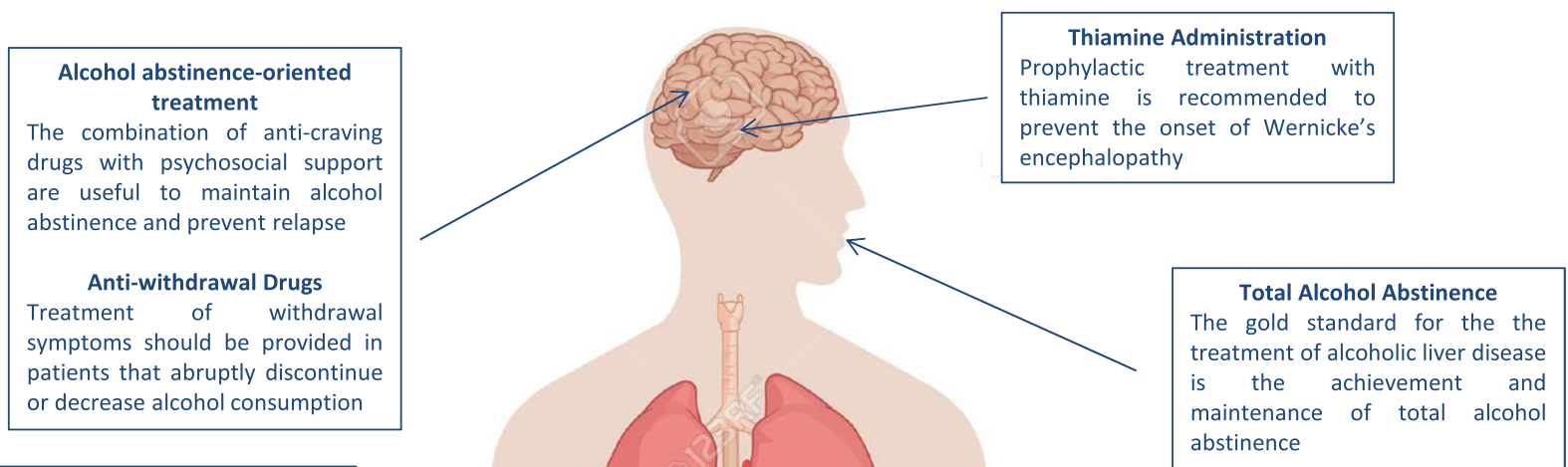

Extra-hepatic alcohol-related disease All patients should be screened and eventually treated for extra-hepatic alcohol-related damage

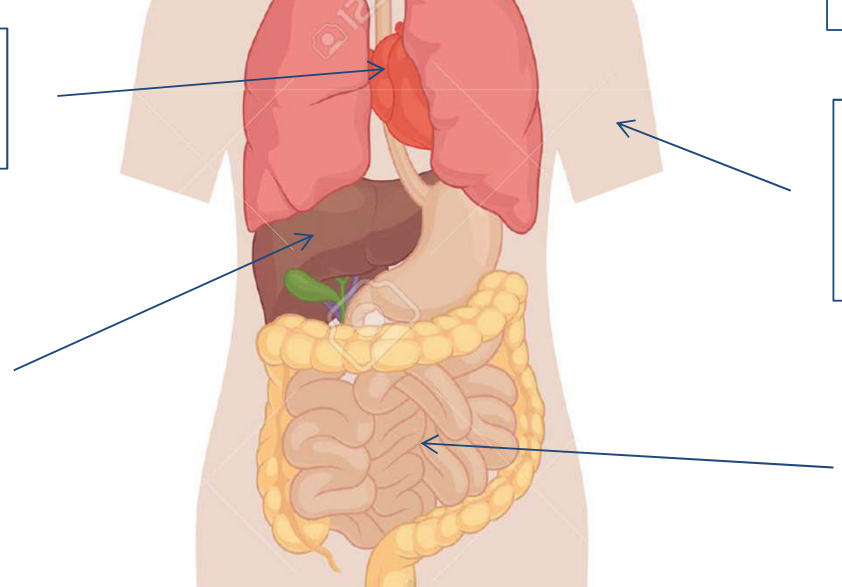

Nutritional Support Adequate protein intake coupled with multivitamin complexes is crucial given the high rate of malnutrition and its related mortality

Antioxidants and Metadoxine metadoxine could be useful to reduce alcohol-induced oxidative stress

Corticosteroids

Corticosteroids are useful in severe forms of alcoholic hepatitis although a recent trial have been questioned their efficacy

Fig. 1 Targets for the treatment of patients with alcohol use disorders and liver disease

Modulation of Gut Microbiota Therapeutic modulation of gut microbiota might be an adjunctive strategy for the treatment of alcoholic liver disease intake (1-1.5 g/kg/day) coupled with multivitamin complexes should be provided [44]. Considering the potential risk of Wernicke's encephalopathy, prophylactic treatment with thiamine (thiamine $250 \mathrm{mg} /$ day for 3-5 consecutive days) is recommended in all AUD patients especially in those with signs of malnutrition [45].

However, the efficacy of medical and surgical treatments for ALD is limited when drinking continues [11, 28]. Thus, the cornerstone for the treatment of ALD is the achievement and maintenance of total alcohol abstinence.

\section{Pharmacological Treatment of AUD in Patients with Liver Disease: from the Management of Alcohol Withdrawal Syndrome to the Relapse Prevention}

At present, AUD is considered a continuum of diseases ranging from mild-to-moderate forms (previously called harmful drinking and alcohol abuse) to severe forms (previously, alcohol dependence). Defining goals of treatment (reduction of alcohol consumption versus total alcohol abstinence) is crucial to decide the most appropriate intervention. However, in the presence of organ damage (i.e., liver disease), the unique option is represented by total alcohol abstinence. This objective requires an integrated approach by physicians with expertise in AUD, with the availability of both inpatient units and outpatient settings.

First step in the management of AUD patients is the treatment of alcohol withdrawal syndrome (AWS), a potentially life-threatening medical condition developing in those patients who abruptly discontinue or decrease alcohol consumption. Symptoms usually develop within 6-24 h after the last drink and include tremors, irritability, anxiety, headache, nausea, and an increase in blood pressure and pulse rate. The severe form of AWS is also characterized by delirium, seizures and coma, a condition called "delirium tremens" that could lead to death [46]. Benzodiazepines represent the gold standard treatment for moderate-to-severe forms of AWS, given their efficacy to reduce both withdrawal symptoms and the risk of developing seizures and/or delirium tremens [47]. Different benzodiazepines and different regimens may be chosen, considering patients' characteristics [46]. Long-acting benzodiazepines, such as diazepam and chlordiazepoxide, provide more protection against seizures and delirium [26]. However, both diazepam and chlordiazepoxide are metabolized by the liver producing active metabolites that make them risky in terms of drug accumulation and excess of sedation in 
patients with advanced LD. Consequently, intermediateacting benzodiazepines with renal metabolism (i.e., lorazepam, oxazepam) could be safer and should be preferred in these patients [26]. Regarding administration schedule, "symptoms-triggered schedule" (administrating the drug at the recurrence of withdrawal symptoms) could be preferred to "fixed-dose schedule" (administrating the drug according to a predefined scheme) in patients with underlying LD, in order to prevent excess of sedation [48].

Given the potential side effects of benzodiazepines in patients with LD, such as hepatic encephalopathy [49], preliminary research has been conducted to identify new medications for AWS. Baclofen, based on its safety hepatic profile [50], seems to be a promising treatment agent for the treatment of AWS in patients with LD. The efficacy of baclofen in the treatment of AWS has been reported by 3 small randomized controlled trials (RCTs) [51-54]. The first study, with singleblind design, compared baclofen (10 mg t.i.d. for 10 days) and diazepam administration $(0.5-0.75 \mathrm{mg} / \mathrm{kg} /$ day for 6 consecutive days, tapering the dose by $25 \%$ daily from day 7 to day 10), showing no significant differences between these drugs in terms of CIWA-Ar score reductions [51]. The second study, with double-blind placebo-controlled design, showed that the use of baclofen was associated with a significant reduction in the use of "as-needed" lorazepam [52]. Finally, the third study compared baclofen with chlordiazepoxide in uncomplicated alcohol withdrawal [53]. A similar reduction in AWS was found in both groups of treated patients [53].

At present, the evidence for recommending baclofen administration for AWS is insufficient [54] and larger studies are necessary before promoting baclofen for this purpose. However, the good safety profile of baclofen in patients with ALD, including cirrhosis, suggests that it may have a potential role in managing AWS in this group of patients [55].

In patients with neuro-autonomic manifestations of AWS, not adequately controlled by benzodiazepine administration, the use of adjunctive treatment is warranted. $\alpha_{2}$-agonists and $\beta$-blockers could be used to treat neuro-autonomic hyperactivity (i.e., tachycardia and hypertension), while anticonvulsant could be used for patients who develop seizures [46]. Neuroleptics are generally used in the management of hallucinations and delirium. However, given their facilitating effect on the development of seizures and the risk of QT prolongation, its use should be limited as adjunctive treatment in the case of agitation, or perceptual disturbances, not adequately controlled by benzodiazepines [46]. Treatment of AWS also includes prevention of Wernicke's encephalopathy, correction of fluid, hypoglycemia and electrolyte balance disorders.

After treatment of AWS, it is mandatory that AUD patients, particularly those affected by LD, start a long-term alcohol abstinence-oriented treatment to prevent relapse. Alcohol discontinuation is able to improve the clinical course of the disease and the overall survival [56] while the persistence of alcohol consumption is the main risk factor for progression of liver damage and complications [11, 28]. Medical recommendations, brief motivational interventions and/or psychosocial approach alone, although essential components for AUD treatment, may not be sufficient to induce total alcohol abstinence and to prevent relapse. The addition of effective pharmacological treatment for AUD (Table 2, Figs. 2 and 3) could be very useful in these patients [57]. However, pharmacological treatment of AUD patients with LD is different from those without LD, mainly because the impaired hepatic function affects drug metabolism, increasing the risk of accumulation with possible toxic effects and possible drug-related hepatotoxicity [58]. Moreover, in terms of safety of pharmacological treatments available for AUD, pieces of evidence lack in patients with LD [26] and this represents the main impediment for their administration. In fact, such individuals are usually excluded from clinical trials with anti-alcohol drugs, because these medications might worsen LD.

Disulfiram, an inhibition of acetaldehyde dehydrogenase, was the first drug approved for AUD treatment. In actively drinking patients, disulfiram induces an unpleasant physiologic reaction called "acetaldehyde syndrome" reinforcing the individual's desire to stop drinking [59]. A recent meta-analysis, including 22 studies, showed a higher success rate of disulfiram compared to controls. However, only open-label trials showed a significant superiority over controls while RCTs with blind designs showed no efficacy of disulfiram [60]. Moreover, disulfiram can cause severe drug-induced liver injury in patients with existing liver disease; therefore, it is contraindicated in these patients $[26,61]$.

In the last decades, the growing understanding of the neurobiology of AUD has led to the development of effective anticraving drugs [57]. Among them, only naltrexone ( $\mu$ opiate receptor antagonist) and acamprosate (NMDA receptor agonist) are approved by the Food and Drug Administration (FDA) [62]. A recent meta-analysis compared these drugs, showing that acamprosate had a significantly larger effect size than naltrexone on the maintenance of abstinence, and naltrexone had a larger effect size than acamprosate on the reduction of heavy drinking and craving [63]. In an observational study [64], administration of naltrexone was only rarely associated with liver enzyme elevation, while naltrexone long-acting formulation (intramuscular) may produce less hepatotoxicity than oral. Therefore, neither of the drugs is indicated in patients with advanced LD [26, 61].

Acamprosate has a good safety profile [65]. The absence of liver metabolism and pharmacokinetic interactions with alcohol could be an advantage in the treatment of AUD patients affected by LD. Results of a preliminary study suggested that acamprosate administered for 1 day was well tolerated in patients with Child-Pugh class A and B cirrhosis [66]. However, no trials with repeated administrations of acamprosate in patients with LD have been conducted. According to the clinical 


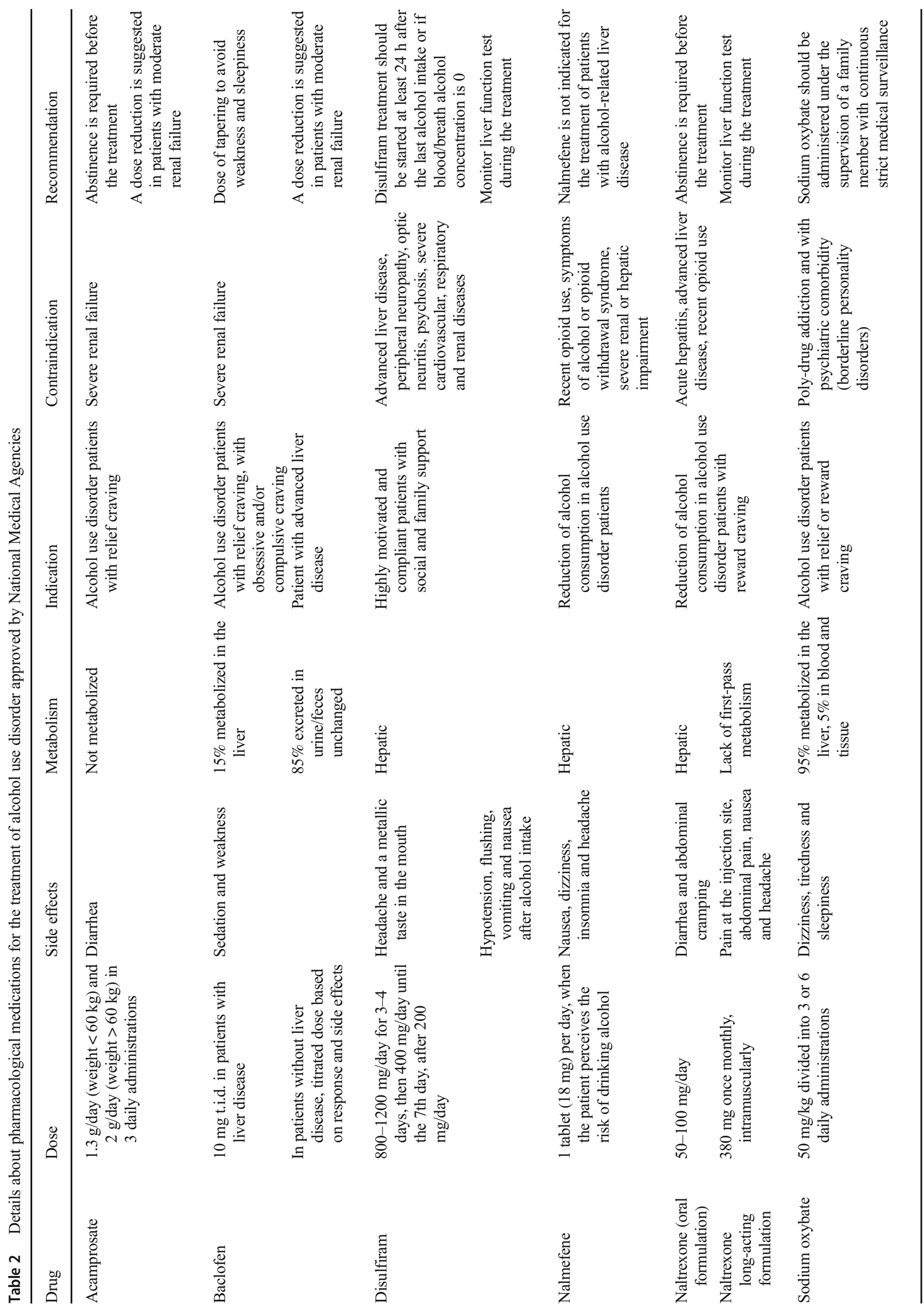



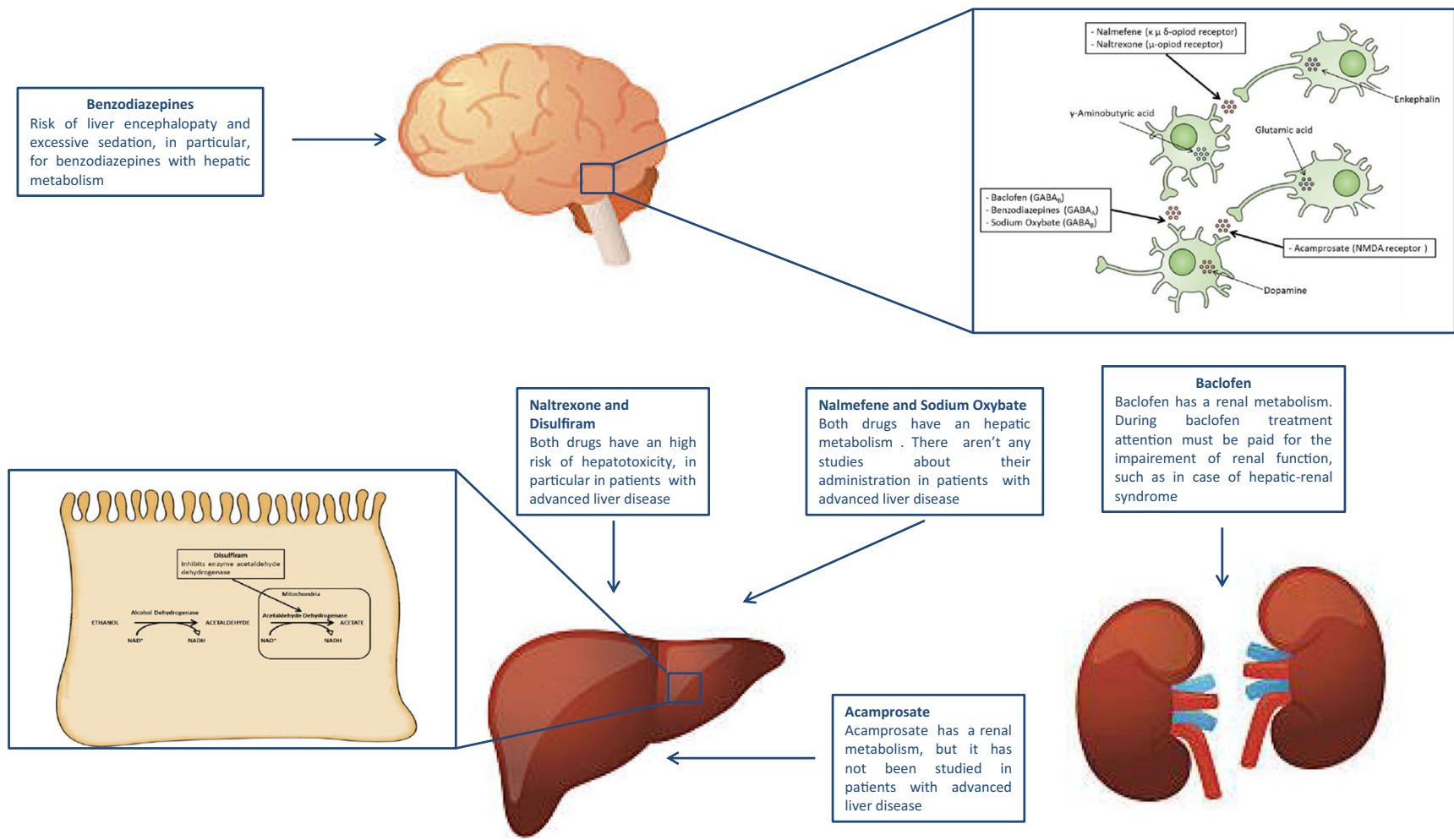

Fig. 2 Target and possible complications of pharmacological treatment for alcohol use disorders in patients with liver disease

practice guidelines of European Association for the Study of Liver Disease, acamprosate and naltrexone could be used only in patients with early liver disease (hepatic steatosis, light/mild fibrosis) [26].

Recently, nalmefene, a K-opioid partial agonist, $\mu$-opioid antagonist and $\delta$-opioid antagonist, was approved by the European Medicines Agency for reducing heavy drinking in patients with AUD after the results of 2 large double-blind RCTs (ESENSE 1 and 2), showing that nalmefene significantly reduced the number of heavy drinking days and mean daily total alcohol consumption [67, 68]. Long-term efficacy and safety of nalmefene was subsequently reported [69]. Its use is not recommended in patients with $\mathrm{LD}$, because nalmefene has not been formally tested in this population and this drug is approved only for the reduction of heavy alcohol intake.

About GABAergic medication approved for the treatment of AUD, sodium oxybate was approved only in Italy and Austria [70, 71], after studies showing its efficacy conducted in these countries. Because of sodium oxybate hepatic metabolism and the scarcity of studies about its administration in patients with LD, its use is indicated in AUD patients without LD.

Baclofen, another GABAergic medication, was approved in France in 2018 [72]. Baclofen is effective in AUD patients in promoting alcohol abstinence and preventing relapse
[73-76]. Given its primary renal metabolism and the low liver metabolism (about $15 \%$ ), its use for treatment of AUD in patients with advanced LD was hypothesized and investigated [50]. A first RCT showed the safety and the efficacy of baclofen at the dose of $10 \mathrm{mg}$ t.i.d. in promoting abstinence in AUD patients with liver cirrhosis [50]. In this study, cumulative abstinence duration and percentage of totally abstinent patients were significantly higher in the baclofen-treated group with respect to the placebo treated group. The drug was tolerated and no significant side effects were reported. The safety profile of baclofen in cirrhotic patients was recently supported by a recent study [77]. In the latter study, patients received baclofen for at least 12 months at a mean dosage of $40 \mathrm{mg} /$ day. The median daily alcohol consumption reduced from 80 to $0 \mathrm{~g}$ /day; no liver or renal function deterioration occurred in cirrhotic patients [77].

Subsequently, 2 RCTs with contrasting results were published. In the former, a total of 180 US veterans affected by AUD and chronic hepatitis $C$ virus infection were randomized to baclofen treatment $(30 \mathrm{mg} /$ day) or placebo for 12 weeks [78]. The study did not show any superiority of $30 \mathrm{mg}$ of baclofen over placebo. However, the patients enrolled in this study were affected by psychiatric comorbidities and use of illicit drugs, so these results cannot be generalized on the overall AUD population. The latter, named BacALD, 


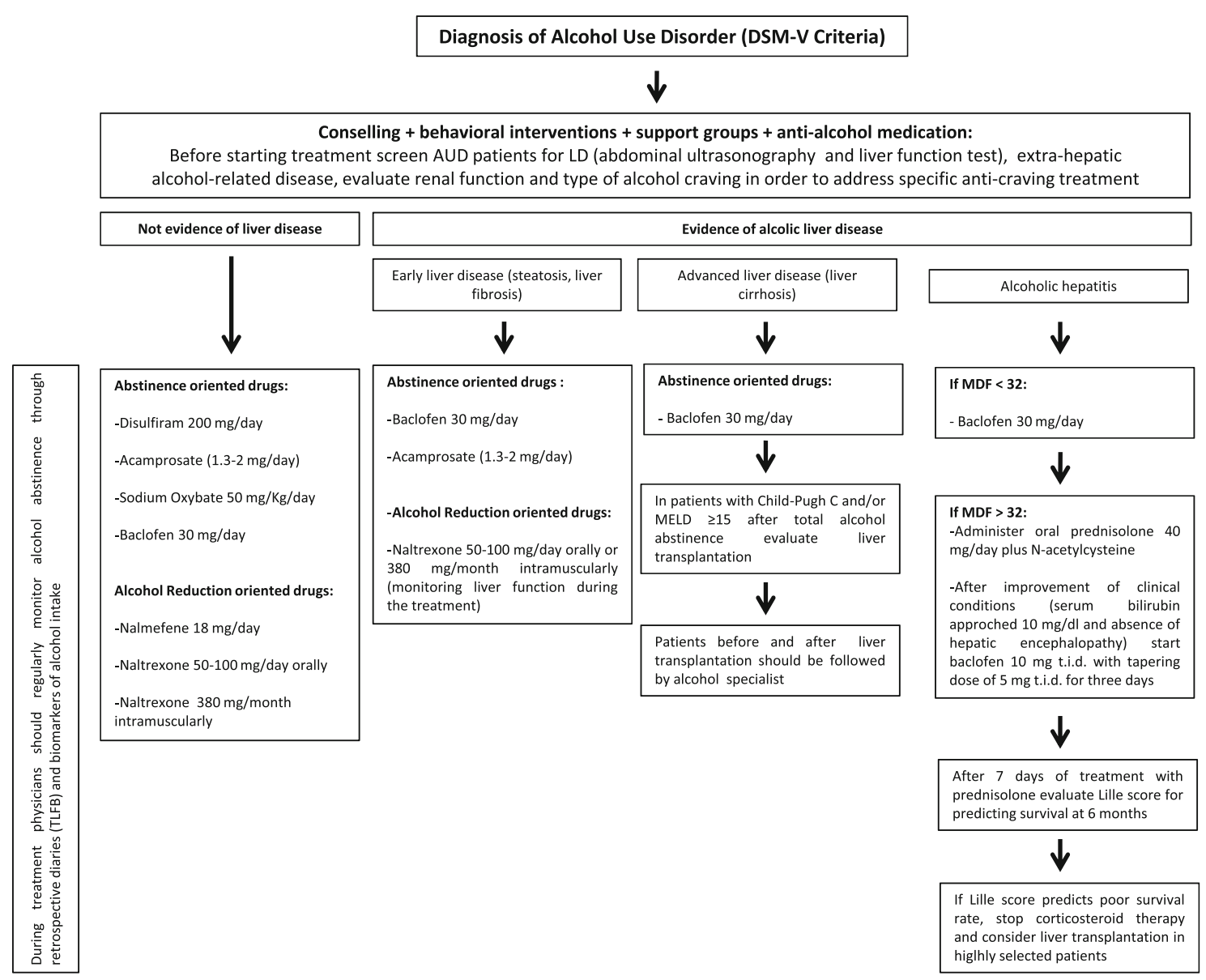

In this algorithm was illustrated the management of Alcohol Use Disorder according the degree of liver disease

Fig. 3 Flowchart of the diagnosis of alcohol use disorder

investigated the efficacy and safety of 2 fixed doses of baclofen $(30 \mathrm{mg} /$ day and $75 \mathrm{mg} /$ day $)$ in AUD patients with or without liver cirrhosis. With respect to placebo, a significant efficacy of baclofen on time to lapse and relapse was found, with no difference between the 2 doses of the drug. The study confirmed the efficacy and safety of the low dose of the drug [79]. Although further studies are needed to confirm these findings, baclofen represents the only anticraving medication formally tested in RCTs in AUD patients with advanced LD [80]. This medication has been included in the European [26, 51] and American $[81,82]$ clinical practice guidelines for the treatment of ALD, and according to a recent consensus document, it could be considered the first line treatment in patients with advanced LD [83].

Other drugs seem to be able to reduce alcohol consumption [84], but they are not approved by the National Medicines Agency for this indication. Among them, topiramate, ondansetron, gabapentin and doxazosin seem to be promising [48]. Topiramate, an anticonvulsant medication, has showed its safety and efficacy in reducing heavy drinking in a randomized controlled trial [85]. A subsequent multisite randomized controlled trial showed as its administration reduces liver enzyme levels [86]. However, this drug has not been tested in patients with LD and its use in this population is, at the moment, not recommended. Further trials should be performed in order to investigate the safety profile of these medications, particularly in patients with LD.

Despite alcohol abstinence is the most important predictor for determining long-term survival in patients with acute alcoholic hepatitis [87], trials investigating the use of anticraving drugs in this setting are currently lacking because of a tendency to exclude patients with severe liver failure. Only a single-center, open, retrospective study analyzed the effects of baclofen in patients with acute alcoholic hepatitis, showing the improvement of liver function tests and confirming its hepatic safety profile [88]. Randomized prospective studies regarding the use of baclofen are needed to confirm its efficacy and safety in this population.

Finally, few data are available on possible pharmacological treatment for AUD in liver-transplanted patients. At present, only a single randomized clinical trial was performed. However, these trials failed the enrollment because patients refused treatments with anticraving drugs [89]. The main reason limiting recruitment to trial of transplanted patients is their 
concern related to possible drug-induced hepatotoxicity [8, 90]. Further studies are needed to investigate the efficacy and safety of anticraving drugs to prevent relapse in transplanted patient.

\section{Psychosocial Approaches for AUD Patients with Liver Disease}

Psychosocial interventions are psychologically based interventions aimed to induce and maintain alcohol abstinence. The large Combining Medications and Behavioral Intervention (COMBINE) study showed how combination of psychosocial support with anticraving medication was significantly superior to pharmacological treatment alone in terms of percentage days abstinent and risk of a heavy drinking day [91]. The most frequently used psychosocial interventions for AUD treatment include 12-step facilitation therapy, motivational enhancement therapy (MET) and cognitive behavioral therapy (CBT). The 12-step facilitation therapy is directed to achieve and maintain alcohol abstinence by encouraging motivation to stop drinking [92]. The 12-step facilitation therapy also involves participation in Alcoholics Anonymous meetings. The MET is a brief treatment which works by increasing the motivational levels in the AUD patients through regular counseling sessions [93]. CBT is a type of psycho-interventional approach which focuses on building self-confidence through regular counseling sessions [94]. These 3 types of psychosocial approaches were compared in a study, named MATCH, showing no difference in drinking outcome between them [95].

Finally, brief interventions and Brief Behavioral Compliance Enhancement Treatment (BBCET) represent a counseling strategy aimed at increasing patient's motivation to abstain from alcohol [48] and an effective tool to enhance patient's compliance to medications [96].

However, these approaches have been mainly tested in AUD patients without LD. AUD patients with LD are special population due to sense of guilt for the development of LD, poor understanding of their addiction, the presence of healthrelated impediments to attend rehabilitation program and difficulty in achieving or maintaining abstinence despite being at risk of life-threatening hepatic decompensation [10]. Because of these characteristics, those patients might respond differently to psychosocial interventions. Moreover, psychosocial therapy became crucial in patients with LD considering the limited available pharmacological treatment. Very few studies evaluating the different types of psychosocial approaches have been conducted in AUD patients with alcoholic liver disease [97, 98] and coinfection of hepatitis $C$ virus [99-101]. Results from these studies were analyzed in a recent systematic review [10], showing that in AUD patients with chronic LD, no robust evidence for any psychosocial intervention alone in maintaining abstinence emerged, while when integrating CBT or MET, and medical care, significant effects were observed both in inducing and maintaining abstinence. These data underline that AUD patients with LD are a special population which benefits from integration of alcohol interventions with medical care. This result confirms the hypothesis that AUD patients with LD are a special subgroup that needs intensive behavioral approaches integrated within medical care.

A further special subgroups of AUD patients are those in waiting list for liver transplantation and those already transplanted. In fact, AUD patients waiting liver transplantation usually underestimate their drinking for a sense of guilt, for fear of upsetting their family and for the risk to be excluded from a list for liver transplantation. AUD patients transplanted should avoid alcohol consumption because it could increase the risk of relapse after liver transplantation, with consequent decreased graft survival, advanced allograft fibrosis and longterm patient survival [102-104]. Few studies have investigated the optimal psychosocial treatment for these patients [105-107]. In fact, these patients are often excluded by trials for their features or because they refuse to be enrolled for their lacking interest in these studies [8]. Moreover, these studies have some limitations and their results are often controversial. At present, 2 psychosocial integrated approaches within medical care have been evaluated [108, 109]. The study of Addolorato and colleagues shows as an approach managed by a team of physicians and psychologists with expertise in addiction medicine and liver disease, integrated within the liver transplantation team reduce the prevalence of relapse and mortality after liver transplantation. These data have been subsequently replicated [110].

Despite evidence that drinking outcomes improve with a combination of pharmacological treatment and psychosocial approaches [91], given the limited available pharmacological treatment for AUD patients with LD, only few studies reported concomitant use of both $[10,100,101,108,111]$. However, the high heterogeneity of these studies, the different types of treatment tested and the number of patients do not allow to assess the efficacy of the combination between both approaches. Future prospective studies are needed to assess the efficacy of concomitant psychosocial approach with anticraving drugs in patients with LD.

\section{Follow-up}

Alcohol use disorders commonly have a relapsing-remitting course. AUD patients, particularly those affected by LD, should be regularly followed in order to prevent relapse. Which professional health figure should follow these patients and the optimal setting need still to be defined. To this date, in some centers, AUD patients with LD are followed by internists, while in others, psychiatrists are the main actors. AUD is 
a complex disease, its management ranges from psychological and clinical evaluation; moreover, AUD patients with advanced $L D$ represent a special population. In order to increase relapse prevention and survival, it is conceivable that these patients need to be managed by a team of clinicians, with expertise in both hepatology and addiction medicine, and psychologists; in this team, psychiatrists could serve as consultant. This model, initially proposed by Addolorato and coworkers [108], has been recently replicated [111, 112], although future studies are needed to clarify the most appropriate setting to manage these patients. During follow-up, clinicians should monitor the pharmacological treatment, in order to optimize most appropriate anticraving medications and to detect the possible side effects. The alcohol timeline followback (TLFB) interview [113] and direct biological markers of alcohol could help to assess alcohol abstinence and/or alcohol relapse. Alcohol abstinence should be evaluated during each outpatient visit, with the possible help of family member or patient's caregiver. At the same time, the possible progression of liver disease and complications of liver cirrhosis, including the risk of hepatocellular carcinoma [114], must be monitored during the follow-up. ALD is the second most common risk factor for HCC in the USA, after hepatitis C [115]. During the follow-up, the use of abdominal ultrasonography in conjunction with serum measurement of the alpha-fetoprotein level every 6 months is strictly recommended [116]. Finally, extrahepatic alcohol-related diseases as nutritional [44], cardiovascular [117], and neurological [45] disorders have an important impact on the prognosis of these patients and therefore need to be appropriately managed.

During follow-up, patients who do not significantly improve despite of alcohol abstinence, particularly those with decompensated liver disease (Child-Pugh $\mathrm{C}$ and/or MELD $\geq 15$ ), should be listed for liver transplantation [8, 26, 118]. A 6-month period of abstinence before listing patients is recommended to prevent unnecessary liver transplantation in patients who will spontaneously improve [26, 61]. However, according to the last International Liver Transplantation Society (ILTS) guideline when medical urgency does not allow a 6-month waiting time, the LT evaluation may proceed in selected patients with shorter periods of abstinence [26, 119]. After transplantation, AUD patients should be regularly screened for upper airway and gastrointestinal tract cancer and they should be advised to quit smoking [120].

\section{Translation Implication}

Translational research is the process of transforming discoveries from basic to clinical research and from clinical research to clinical practice. In the past years, neurobiological and behavioral research studies have led to the discovery of effective AUD treatments and continue to progress in this field [57].
Moreover, translational research studies on application of new biological markers in clinical practice and treatment to prevent/reduce alcohol-related damage (e.g., modulation of gut microbiota) are in progress. A big challenge of translational research on AUD is the implementation and dissemination of public health interventions. In fact, only a few AUD patients receive treatment [9]. These data highlight the need for translational research aiming to ensure that these interventions are delivered to all AUD patients.

\section{Perspective and Future Challenges}

Despite anticraving drugs have been shown to be costeffective and the need of alcohol abstinence-oriented treatment in patients with $\mathrm{LD}$, only $<10 \%$ of patients receive these treatments [9]. The main reasons for this underused pharmacological treatment are the poor understanding of the underlying disease and fear by patients to use medications, the lack of knowledge or familiarity with anticraving drugs by hepatologists that usually manage these patients and little integration of AUD specialists into the medical teams that take care of these patients [50]. Efforts should be made to overcome the current barriers to treatment, promoting anticraving drugs among physicians and integrating AUD specialist in the team in charge of these patients.

Acknowledgments The authors are grateful to Ms. Caterina Mirijello for her expert revision of the English language.

Required Author Forms Disclosure forms provided by the authors are available with the online version of this article.

Author Contributions G. Addolorato, G.A. Vassallo, and A. Mirijello interpreted the literature data. G. Addolorato, G.A. Vassallo, A. Mirijello, and A. Gasbarrini thought the scientific rationale and wrote and revised the paper. G. Addolorato and A. Gasbarrini revised the final version of the paper. Each one of the authors has contributed to the writing and reviewing of the paper and approved the final version.

\section{Compliance with Ethical Standards}

Conflict of Interest The authors declare that they have no conflict of interests.

Guarantor of the article: Giovanni Addolorato.

\section{References}

1. Rehm J, Mathers C, Popova S, et al. Global burden of disease and injury and economic cost attributable to alcohol use and alcoholuse disorders. Lancet. 2009 Jun 27;373(9682):2223-33

2. WHO. Global health risks-2011. Geneva, World Health Organization

3. WHO. Global Status Report on Alcohol and Health-2018. Geneva, World Health Organization 
4. WHO. Global Status Report on Alcohol and Health - 2014. Geneva, World Health Organization

5. Tilg H, Day CP. Management strategies in alcoholic liver disease. Nat Clin Pract Gastroenterol Hepatol. 2007; 4(1):24-34

6. Stein E, Cruz-Lemini M, Altamirano J, et al. Heavy daily alcohol intake at the population level predicts the weight of alcohol in cirrhosis burden worldwide. J Hepatol. 2016; 65(5):998-1005

7. Dugum M, McCullough A. Diagnosis and Management of Alcoholic Liver Disease. J Clin Transl Hepatol. 2015; 3(2):109 16

8. Lucey MR. Liver transplantation for alcoholic liver disease. Nat Rev Gastroenterol Hepatol. 2014; 11(5):300-7

9. Goh ET, Morgan MY. Review article: pharmacotherapy for alcohol dependence - the why, the what and the wherefore. Aliment Pharmacol Ther. 2017; 45(7):865-82

10. Khan A, Tansel A, White DL, et al. Efficacy of Psychosocial Interventions in Inducing and Maintaining Alcohol Abstinence in Patients With Chronic Liver Disease: A Systematic Review. Clin Gastroenterol Hepatol. 2016; 14(2):191-202

11. Addolorato G, Mirijello A, Barrio P, Gual A. Treatment of alcohol use disorders in patients with alcoholic liver disease. J Hepatol. 2016; 65(3):618-30

12. Hagman BT. Performance of the AUDIT in Detecting DSM-5 Alcohol Use Disorders in College Students. Subst Use Misuse. 2016; 51(11):1521-8

13. Ewing JA. Detecting alcoholism. The CAGE questionnaire. JAMA. 1984; 252(14):1905-7

14. Saunders JB, Aasland OG, Babor TF, de la Fuente JR, Grant M. Development of the Alcohol Use Disorders Identification Test (AUDIT): WHO Collaborative Project on Early Detection of Persons with Harmful Alcohol Consumption-II. Addiction. 1993; 88(6):791-804

15. Connor JP, Haber PS, Hall WD. Alcohol use disorders. Lancet. 2016; 387(10022):988-98

16. Maisto SA, Saitz R. Alcohol use disorders: screening and diagnosis. Am J Addict. 2003; 12(suppl 1):S12-25

17. American Psychiatry Association. Diagnostic and Statistical Manual of Mental Disorders, V Edition. American Psychiatry Association, 2013 Washington, DC, USA

18. Kummer N, Lambert WE, Samyn N, Stove CP. Alternative sampling strategies for the assessment of alcohol intake of living persons. Clin Biochem. 2016; 49(13-14):1078-91

19. Berlakovich GA, Soliman T, Freundorfer E, et al. Pretransplant screening of sobriety with carbohydrate-deficient transferrin in patients suffering from alcoholic cirrhosis. Transpl Int. 2004; 17: $617-21$

20. Allen JP, Wurst FM, Thon N, Litten RZ. Assessing the drinking status of liver transplant patients with alcoholic liver disease. Liver Transpl. 2013; 19:369-76

21. Andresen-Streichert $\mathrm{H}$, von Rothkirch $\mathrm{G}$, Vettorazzi E, et al. Determination of Ethyl Glucuronide in Hair for Detection of Alcohol Consumption in Patients After Liver Transplantation. Ther Drug Monit. 2015; 37(4):539-45

22. Piano S, Marchioro L, Gola E, et al. Assessment of alcohol consumption in liver transplant candidates and recipients: the best combination of the tools available. Liver Transpl. 2014; 20(7): $815-22$

23. Stewart SH, Koch DG, Willner IR, Anton RF, Reuben A. Validation of blood phosphatidylethanol as an alcohol consumption biomarker in patients with chronic liver disease. Alcohol Clin Exp Res. 2014; 38(6):1706-11

24. Andresen-Streichert H, Beres Y, Weinmann W, et al. Improved detection of alcohol consumption using the novel marker phosphatidylethanol in the transplant setting: results of a prospective study. Transpl Int. 2017; 30(6):611-620
25. Barrio P, Wurst FM, Gual A. New Alcohol Biomarkers. New challenges. Alcohol Alcohol. 2018; 53(6):762-3

26. European Association for the Study of Liver. EASL clinical practical guidelines: management of alcoholic liver disease. J Hepatol 2018; 69:154-81

27. Louvet A, Mathurin P. Alcoholic liver disease: mechanisms of injury and targeted treatment. Nat Rev Gastroenterol Hepatol. 2015; 12(4):231-42.

28. Altamirano J, Bataller R. Alcoholic liver disease: pathogenesis and new targets for therapy. Nat Rev Gastroenterol Hepatol. 2011; 8(9):491-501

29. Hart CL, Morrison DS, Batty GD et al. Effect of body mass index and alcohol consumption on liver disease: analysis of data from two prospective cohort studies. BMJ. 2010; 340:c1240

30. Li S, Tan HY, Wang N, et al. The Role of Oxidative Stress and Antioxidants in Liver Diseases. Int J Mol Sci. 2015; 16:26087124

31. Addolorato G, Ancona C, Capristo E, Gasbarrini G. Metadoxine in the treatment of acute and chronic alcoholism: a review. Int J Immunopathol Pharmacol. 2003; 16:207-14

32. Caballeria $\mathrm{J}$, Parés $\mathrm{A}, \mathrm{Brù} \mathrm{C}$, et al. Metadoxine accelerates fatty liver recovery in alcoholic patients: results of a randomized double-blind, placebo control trial. Spanish group for the study of alcoholic fatty liver. J Hepatol. 1998; 28:54-60

33. Bjørkhaug ST, Aanes H, Neupane SP, et al. Characterization of gut microbiota composition and functions in patients with chronic alcohol overconsumption. Gut Microbes. 2019; 20:1-13

34. Vassallo G, Mirijello A, Ferrulli A, et al. Review article: Alcohol and gut microbiota - the possible role of gut microbiota modulation in the treatment of alcoholic liver disease. Aliment Pharmacol Ther. 2015; 41(10):917-27

35. Posteraro B, Paroni Sterbini F, et al. Liver Injury, Endotoxemia, and Their Relationship to Intestinal Microbiota Composition in Alcohol-Preferring Rats. Alcohol Clin Exp Res. 2018; 42(12): 2313-25

36. Maddrey WC, Boitnott JK, Bedine MS, et al. Corticosteroid therapy of alcoholic hepatitis. Gastroenterology. 1978 Aug; 75(2): 193-9

37. Forrest EH, Evans CD, Stewart S, et al. Analysis of factors predictive of mortality in alcoholic hepatitis and derivation and validation of the Glasgow alcoholic hepatitis score. Gut. 2005 Aug; 54(8):1174-9

38. Mathurin P, Lucey MR. Management of alcoholic hepatitis. J Hepatol. 2012; 56 Suppl 1:S39-45

39. Thursz MR, Richardson P, Allison M, et al; STOPAH Trial. Prednisolone or pentoxifylline for alcoholic hepatitis. N Engl J Med. 2015; 372(17):1619-28

40. Singh S, Murad MH, Chandar AK, et al. Comparative effectiveness of pharmacological interventions for severe alcoholic hepatitis: a systematic review and network meta-analysis. Gastroenterology. 2015; 149:958-70

41. Nguyen-Khac E, Thevenot T, Piquet MA, et al. Glucocorticoids plus $\mathrm{N}$-acetylcysteine in severe alcoholic hepatitis. N Engl J Med. 2011; 365:1781-89

42. Louvet A, Diaz E, Dharancy S, et al. Early switch to pentoxifylline in patients with severe alcoholic hepatitis is inefficient in nonresponders to corticosteroids. J Hepatol. 2008; 48:465-70

43. Singal AK, Charlton MR. Nutrition in alcoholic liver disease. Clin Liver Dis. 2012; 16(4):805-26

44. Rossi RE, Conte D, Massironi S. Diagnosis and treatment of nutritional deficiencies in alcoholic liver disease: Overview of available evidence and open issues. Dig Liver Dis. 2015; 47(10):819 25

45. Sechi G, Serra A. Wernicke's encephalopathy: new clinical settings and recent advances in diagnosis and management. Lancet Neurol. 2007; 6(5):442-55 
46. Mirijello A, D'Angelo C, Ferrulli A, et al. Identification and management of alcohol withdrawal syndrome. Drugs. 2015; 75(4): $353-65$

47. Amato L, Minozzi S, Davoli M. Efficacy and safety of pharmacological interventions for the treatment of the Alcohol Withdrawal Syndrome. Cochrane Database Syst Rev. 2011; (6):CD008537

48. Leggio L, Lee MR. Treatment of Alcohol Use Disorder in Patients with Alcoholic Liver Disease. Am J Med. 2017; 130(2):124-134

49. American Association for the Study of Liver Diseases; European Association for the Study of the Liver. Hepatic encephalopathy in chronic liver disease: 2014 practice guideline by the European Association for the Study of the Liver and the American Association for the Study of Liver Diseases. J Hepatol. 2014; 61(3):642-59

50. Addolorato G, Leggio L, Ferrulli A, et al. Effectiveness and safety of baclofen for maintenance of alcohol abstinence in alcoholdependent patients with liver cirrhosis: randomised, double-blind controlled study. Lancet. 2007; 370:1915-22

51. Addolorato G, Leggio L, Abenavoli L, et al. Baclofen in the treatment of alcohol withdrawal syndrome: a comparative study vs diazepam. Am J Med. 2006; 119(3):276.e13-8

52. Lyon JE, Khan RA, Gessert CE, Larson PM, Renier CM. Treating alcohol withdrawal with oral baclofen: a randomized, doubleblind, placebo-controlled trial. J Hosp Med. 2011; 6:469-74

53. Girish K, Reddy VK, Pandit LV, et al. A randomized, open-label, standard controlled, parallel group study of efficacy and safety of baclofen, and chlordiazepoxide in uncomplicated alcohol withdrawal syndrome. Biomed J. 2016; 39(1):72-80

54. Liu J, Wang LN. Baclofen for alcohol withdrawal. Cochrane Database Syst Rev. 2015; 4:CD008502

55. Cooney G, Heydtmann M, Smith ID. Baclofen and the Alcohol Withdrawal Syndrome-A Short Review. Front. Psychiatry. 2019; 9:773

56. Xie YD, Feng B, Gao Y, Wei L. Effect of abstinence from alcohol on survival of patients with alcoholic cirrhosis: A systematic review and meta-analysis. Hepatol Res. 2014; 44:436- 449

57. Addolorato G, Abenavoli L, Leggio L, Gasbarrini G. How many cravings? Pharmacological aspects of craving treatment in alcohol addiction: a review. Neuropsychobiology. 2005; 51(2):59-66

58. Lewis JH, Stine JG. Review article: prescribing medications in patients with cirrhosis - a practical guide. Aliment Pharmacol Ther. 2013 Jun;37(12):1132-56

59. Krampe H, Ehrenreich H. Supervised Disulfiram as Adjunct to Psychotherapy in Alcoholism Treatment. Curr Pharm Des. 2010; 16:2076-90

60. Skinner MD, Lahmek P, Pham H, et al. Disulfiram efficacy in the treatment of alcohol dependence: a meta-analysis. PLoS One. 2014; 9:e87366

61. European Association for the Study of Liver. EASL clinical practical guidelines: management of alcoholic liver disease. J Hepatol. 2012; 57(2):399-420

62. Litten RZ, Egli M, Heilig M, et al. Medications development to treat alcohol dependence: a vision for the next decade. Addict Biol. 2012; 17(3):513-27

63. Maisel NC, Blodgett JC, Wilbourne PL, Humphreys K, Finney JW. Meta-analysis of naltrexone and acamprosate for treating alcohol use disorders: when are these medications most helpful? Addiction. 2013; 108:275-93

64. Tetrault JM, Tate JP, McGinnis KA, et al. Hepatic safety and antiretroviral effectiveness in HIV-infected patients receiving naltrexone. Alcohol Clin Exp Res. 2012; 36:318-24

65. Mason BJ, Heyser CJ. The neurobiology, clinical efficacy and safety of acamprosate in the treatment of alcohol dependence. Expert Opin Drug Saf. 2010; 9:177-88

66. Delgrange T, Khater J, Capron D, et al. Effect of acute administration of acamprosate on the risk of encephalopathy and on arterial pressure in patients with alcoholic cirrhosis. Gastroenterol Clin Biol. 1992; 16:687-91

67. Mann K, Bladström A, Torup L, Gual A, van den Brink W. Extending the treatment options in alcohol dependence: a randomized controlled study of as-needed nalmefene. Biol Psychiatry 2013; 73(8):706-13

68. Gual A, He Y, Torup L, van den Brink W, Mann K; ESENSE 2 Study Group. A randomised, double-blind, placebo-controlled, efficacy study of nalmefene, as-needed use, in patients with alcohol dependence. Eur Neuropsychopharmacol 2013; 23(11):143242

69. Van den Brink W, Sørensen P, Torup L, Mann K, Gual A; SENSE Study Group. Long-term efficacy, tolerability and safety of nalmefene as-needed in patients with alcohol dependence: A 1year, randomised controlled study. J Psychopharmacol. 2014; 28(8):733-44

70. Skala K, Caputo F, Mirijello A, et al. Sodium oxybate in the treatment of alcohol dependence: from the alcohol withdrawal syndrome to the alcohol relapse prevention. Expert Opin Pharmacother. 2014; 15(2):245-57

71. Mirijello A, Caputo F, Vassallo G, et al. GABAB Agonists for the Treatment of Alcohol Use Disorder. Curr Pharm Des. 2015; 21(23):3367-72

72. Agence Nationale de Sécurité du Médicament et des Produits de Santé Avis de la commission mixte ad hoc sur l'évaluation de l'utilisation du baclofène dans le traitement des patients alcoolodépendants. https://ansm.sante.fr/content/download/146361/ 1931039/version/1/file/Avis-Commission-Baclofene-+4-juillet05072018.pdf Date: 2018 Date accessed: October 23, 2018

73. Addolorato G, Caputo F, Capristo E, et al. Ability of baclofen in reducing alcohol craving and intake: II-Preliminary clinical evidence. Alcohol Clin Exp Res. 2000; 24(1):67-71

74. Addolorato G, Caputo F, Capristo E, et al. Baclofen efficacy in reducing alcohol craving and intake: a preliminary double-blind randomized controlled study. Alcohol Alcohol. 2002; 37(5):504-8

75. Addolorato G, Leggio L, Ferrulli A, Baclofen Study Group, et al. Dose-response effect of baclofen in reducing daily alcohol intake in alcohol dependence: secondary analysis of a randomized, double-blind, placebo-controlled trial. Alcohol Alcohol. 2011; 46(3): 312-7

76. Müller CA, Geisel O, Pelz P, et al. High-dose baclofen for the treatment of alcohol dependence (BACLAD study): a randomized, placebo-controlled trial. Eur Neuropsychopharmacol. 2015; 25(8):1167-77

77. Barrault C, Lison H, Roudot-Thoraval F, et al. One year of baclofen in 100 patients with or without cirrhosis: a French real-life experience. Eur J Gastroenterol Hepatol. 2017; 29(10):1155-60

78. Hauser P, Fuller B, Ho SB, et al. The safety and efficacy of baclofen to reduce alcohol use in veterans with chronic hepatitis $\mathrm{C}$ : a randomized controlled trial. Addiction 2017; 112:1173-83

79. Morley KC, Baillie A, Fraser I, Haber PS. Baclofen in the treatment of alcohol dependence with or without liver disease (BacALD): A multi-site, randomised, double-blind, placebocontrolled trial. Br J Psychiatry. 2018; 212:362-9

80. Mosoni C, Dionisi T, Vassallo GA, et al. Baclofen for the Treatment of Alcohol Use Disorder in Patients With Liver Cirrhosis: 10 Years After the First Evidence. Front Psychiatry. 2018; 9:474

81. Runyon BA; AASLD Practice Guidelines Committee. Management of adult patients with ascites due to cirrhosis: an update. Hepatology. 2009; 49(6):2087-107

82. Singal AK, Bataller R, Ahn J, Kamath PS, Shah VH. ACG Clinical Guideline: Alcoholic Liver Disease. Am J Gastroenterol. 2018; 113(2):175-94 
83. Agabio R, Sinclair JM, Addolorato G, et al. Baclofen for the treatment of alcohol use disorder: the Cagliari Statement. Lancet Psychiatry. 2018; 5(12):957-60

84. Edwards S, Kenna, GA, Swift RM, Leggio L. Current and promising pharmacotherapies, and novel research target areas in the treatment of alcohol dependence: a review. Curr Pharm Des. 2011; 17:1323-32

85. Johnson BA, Rosenthal N, Capece JA, et al. Topiramate for treating alcohol dependence: a randomized controlled trial. JAMA. 2007; 298:1641-51

86. Johnson BA, Rosenthal N, Capece JA, et al. Improvement of physical health and quality of life of alcohol-dependent individuals with topiramate treatment: US multisite randomized controlled trial. Arch Intern Med. 2008; 168:1188-99

87. Potts JR, Goubet S, Heneghan MA, Verma S. Determinants of long-term outcome in severe alcoholic hepatitis. Aliment Pharmacol Ther. 2013; 38(6):584-95

88. Yamini D, Lee SH, Avanesyan A, Walter M, Runyon B. Utilization of baclofen in maintenance of alcohol abstinence in patients with alcohol dependence and alcoholic hepatitis with or without cirrhosis. Alcohol Alcohol. 2014; 49(4):453-6

89. Weinrieb RM, Van Horn DH, McLellan AT, et al. Alcoholism treatment after liver transplantation: lessons learned from a clinical trial that failed. Psychosomatics. 2001; 42(2):110-6

90. Weinrieb RM, Van Horn DH, McLellan AT, et al. Drinking behavior and motivation for treatment among alcohol-dependent liver transplant candidates. J Addict Dis. 2001; 20(2):105-19

91. Anton RF, O’Malley SS, Ciraulo DA, et al; COMBINE Study Research Group. Combined pharmacotherapies and behavioral interventions for alcohol dependence: the COMBINE study: a randomized controlled trial. JAMA. 2006; 295(17):2003-17

92. Nowinski J, Baker S, Carroll KM. Twelve step facilitation therapy manual: a clinical research guide for therapists treating individuals with alcohol abuse and dependence. Project MATCH monograph series, vol 2. Rockville: NIAAA; 1995

93. Miller WR, Zweben A, DiClemente CC, et al. Motivational enhancement therapy manual, vol. 2. Rockville: NIAAA 1994

94. Kadden R, Carroll KM, Donovan D, et al. Cognitive-behavioral coping skills therapy manual: a clinical research guide for therapists treating individuals with alcohol abuse and dependence, vol. 3. Rockville: NIAAA 1995

95. Matching alcoholism treatments to client heterogeneity. Project MATCH post-treatment drinking outcomes. J Stud Alcohol. 1997; 58:7-29

96. Johnson BA, DiClemente CC, Ait-Daoud N, et al. Brief behavioral compliance enhancement treatment (BBCET) manual. In: Johnson BA, Ruiz P, Galanter M, editors. Handbook of clinical alcoholism treatment. Baltimore: Lippincott Williams \& Wilkins; 2003; p. 282-301

97. Lieber CS, Weiss DG, Groszmann R, Paronetto F, Schenker S; Veterans Affairs Cooperative Study 391 Group. I. Veterans Affairs Cooperative Study of polyenylphosphatidylcholine in alcoholic liver disease: effects on drinking behavior by nurse/physician teams. Alcohol Clin Exp Res. 2003; 27(11):1757-64

98. Andersen MM, Aunt S, Jensen NM, et al. Rehabilitation for cirrhotic patients discharged after hepatic encephalopathy improves survival. Dan Med J. 2013; 60(8):A4683

99. Drumright LN, Hagan H, Thomas DL, et al. Predictors and effects of alcohol use on liver function among young HCV-infected injection drug users in a behavioral intervention. J Hepatol. 2011; $55(1): 45-52$
100. Proeschold-Bell RJ, Patkar AA, Naggie S, et al. An integrated alcohol abuse and medical treatment model for patients with hepatitis C. Dig Dis Sci. 2012; 57(4):1083-91

101. Dieperink E, Fuller B, Isenhart C, et al. Efficacy of motivational enhancement therapy on alcohol use disorders in patients with chronic hepatitis C: a randomized controlled trial. Addiction. 2014; 109(11):1869-77

102. Rice JP, Eickhoff J, Agni R, et al. Abusive drinking after liver transplantation is associated with allograft loss and advanced allograft fibrosis. Liver Transpl. 2013; 19(12):1377-86

103. Cuadrado A, Fábrega E, Casafont F, Pons-Romero F. Alcohol recidivism impairs long-term patient survival after orthotopic liver transplantation for alcoholic liver disease. Liver Transpl. 2005; 11(4):420-6

104. Pfitzmann R, Schwenzer J, Rayes N, et al. Long-term survival and predictors of relapse after orthotopic liver transplantation for alcoholic liver disease. Liver Transpl. 2007; 13(2):197-205

105. Masson S, Marrow B, Kendrick S, et al. An 'alcohol contract' has no significant effect on return to drinking after liver transplantation for alcoholic liver disease. Transpl Int. 2014; 27(5):475-81

106. Georgiou G, Webb K, Griggs K, et al. First report of a psychosocial intervention for patients with alcohol-related liver disease undergoing liver transplantation. Liver Transpl. 2003; 9:772-5

107. Weinrieb RM, Van Horn DH, Lynch KG, Lucey MR. A randomized, controlled study of treatment for alcohol dependence in patients awaiting liver transplantation. Liver Transpl. 2011; 17(5): $539-47$

108. Addolorato G, Mirijello A, Leggio L, et al; Gemelli OLT Group. Liver transplantation in alcoholic patients: impact of an alcohol addiction unit within a liver transplant center. Alcohol Clin Exp Res. 2013; 37(9):1601-8

109. Björnsson E, Olsson J, Rydell A, et al. Long-term follow-up of patients with alcoholic liver disease after liver transplantation in Sweden: impact of structured management on recidivism. Scand J Gastroenterol. 2005; 40(2):206-16

110. Attilia ML, Lattanzi B, Ledda R, et al. The multidisciplinary support in preventing alcohol relapse after liver transplantation: A single-center experience. Clin Transplant. 2018; 32(5):e13243

111. Dieperink E, Ho S, Heit S, et al. Significant Reductions in Drinking Following Brief Alcohol Treatment Provided in a Hepatitis C Clinic. Psychosomatics. 2010; 51:149-56

112. Heyes CM, Schofield T, Gribble R, Day CA, Haber PS. Reluctance to Accept Alcohol Treatment by Alcoholic Liver Disease Transplant. Patients: A Qualitative Study. Transplant Direct. 2016; 2(10):e104

113. Sobell LC, Maisto SA, Sobell MB, et al. Reliability of alcohol abusers' self-reports of drinking behavior. Behav Res Ther. 1979; 17:157-60

114. Yang JD1, Roberts LR. Hepatocellular carcinoma: A global view. Nat Rev Gastroenterol Hepatol. 2010; 7(8):448-58

115. El-Serag HB, Mason AC. Risk factors for the rising rates of primary liver cancer in the United States. Arch Intern Med. 2000; 160:3227-323

116. Ge PS \& Runyon BA. Treatment of Patients with Cirrhosis. N Engl J Med. 2016; 375(8):767-77

117. Mirijello A, Tarli C, Vassallo GA, et al. Alcoholic cardiomyopathy: What is known and what is not known. Eur J Intern Med. 2017; 43:1-5.

118. Vassallo G, Mirijello A, Antonelli M, Ferrulli A, Addolorato G. Liver transplantation for alcoholic liver disease. J Alcohol Drug Depend. 2013; 2:143. 
119. Addolorato G, Bataller R, Burra P, et al. Liver Transplantation for Alcoholic Liver Disease. Transplantation. 2016; 100(5):981-7

120. Vassallo GA, Tarli C, Rando MM, et al. Liver Transplantation in Patients with Alcoholic Liver Disease: A Retrospective Study. Alcohol Alcohol. 2018; 53(2):151-6.
Publisher's Note Springer Nature remains neutral with regard to jurisdictional claims in published maps and institutional affiliations.

\section{Affiliations}

\section{Giovanni Addolorato ${ }^{1,2} \cdot$ Gabriele A. Vassallo $^{1,3} \cdot$ Antonio Mirijello $^{1,4} \cdot$ Antonio Gasbarrini $^{2,5}$}

1 "Internal Medicine and Alcohol Related Disease" Unit, Department of Internal Medicine and Gastroenterology, Catholic University of Rome, Rome, Italy

2 Fondazione Policlinico Universitario A Gemelli IRCCS Research Hospital, Rome, Italy
Department of Internal Medicine, Barone Lombardo Hospital,

Canicattì, Italy

4 Department of Medical Sciences, IRCCS Casa Sollievo della Sofferenza Hospital, San Giovanni Rotondo, Italy

5 Department of Internal Medicine and Gastroenterology, Catholic University of Rome, Rome, Italy 